\title{
I mproving nursing students research knowledge through participation in a study about nutrition, its associated factors and assessment
}

\author{
Albert Westergren, Ellinor Edfors, Gita Hedin, Peter Hagell \\ The PRO-CARE Group, School of Health and Society, Kristianstad University, Kristianstad, Sweden \\ Correspondence: Albert Westergren. Address: School of Health and Society, Kristianstad University, SE-291 88, \\ Kristianstad, Sweden. Email: Albert.Westergren@hkr.se. \\ Received: October 9, 2012 \\ DOI : $10.5430 /$ jnep.v3n8p50 \\ Accepted: December 4, 2012 \\ URL: http://dx.doi.org/10.5430/jnep.v3n8p50
}

\section{Abstract}

Aims: The aims of this study were threefold: 1) to explore nursing students perceptions of knowledge development after participating in an actual research project; 2) to explore undernutrition and its relationship to other clinical factors; 3) to explore the user-friendliness of the Minimal Eating Observation and Nutrition Form (MEONF-II) in relation to dependency in Activities of Daily Living (ADL).

Methods: A pilot study (Study 1, S1) was conducted in October 2010, including 281 patients. After extending the research protocol a second data collection (S2) was conducted in March 2011, including 236 patients (total $n=517$ ). First and third year nursing students $(\mathrm{n}=188)$ collected the data, during one day of their clinical practice courses by assessing three patients each in hospitals or nursing homes. Students answered questions about their experiences from participating in the study. Patient related assessments included: MEONF-II; ADL dependency (S1 and S2); insomnia; low-spiritedness; and subjective health (S2). In addition, questions about the user-friendliness of MEONF-II were included (S1 and S2).

Results: Among the nursing students, 51\% experienced that their knowledge about nutrition increased and $67 \%$ that their understanding for research increased by participating in the project. Out of the patients, $57 \%$ were women, $50 \%$ were almost independent, $27 \%$ had some dependency, $23 \%$ were almost totally dependent in ADL, and 48\% were at moderate/ high undernutrition risk. In S2, 32\% of patients had insomnia, and 46\% experienced low-spiritedness. Dependency in 5-6 and 3-4 ADLs (OR, 2.439 and 2.057, respectively), compared to dependency in 0-2 ADLs, were the strongest predictors for undernutrition risk, followed by insomnia (OR 2.124). Nursing students experienced the MEONF-II as easy to understand (93\%), easy to answer (94\%) and relevant (94\%), and the suggestions for measures to take in case of risk as relevant (95\%), independent of the patients' ADL status.

Conclusions: By participating in an actual research project nursing students gets an understanding for research and tools for working with quality improvements in their future role as professional nurses. Undernutrition, mental and physical factors constitute coexisting problems in need for further investigation. Nursing students perceive the MEONF-II as user-friendly, independent of patient ADL dependency.

\section{Key words}

Work integrated learning, Undernutrition, MEONF-II, Insomnia, Activities of daily living 


\section{I ntroduction}

In Sweden, higher education has three corner stones; education, research and interaction with the surrounding society ${ }^{[1]}$. By involving nursing students in real research projects it is possible to integrate the three corner stones ${ }^{[2]}$, as was done in this study focusing on screening of nutritional risk using the Minimal Eating Observation Form (MEONF-II ${ }^{[3-5]}$ ). Its relationship to other clinical problems has not been explored and its user friendliness when used by nursing students also remains to be addressed.

Nursing students can learn about research in many different ways. The focus can be either on the process of deducting evidence from research or on how to conduct research. In this study the focus is on "conducting research". By involving students in actual research projects it might be possible to increase their knowledge about research and its usefulness for quality improvement in clinical practice. It has been shown that by having students to participate in the research process their attitudes towards research gets more positive ${ }^{[6]}$ and that their research skills improve ${ }^{[6,7]}$. We have involved undergraduate nursing students in actual research projects since $2005^{[2,8-10]}$. For example, in a small study were the students $(n=42)$ were research collaborators in a nutrition study, $86 \%$ stated that they got improved understanding of research and $38 \%$ got increased knowledge about nutrition ${ }^{[11]}$. However, it was a small study and it would therefore be relevant to explore this further in a larger study. In addition, while the methodology for RECN-assignments (Research, Education and Collaboration integrated in Nursing education) has been improved since that study the general focus on research in nursing education has increased, which makes it worthwhile to explore whether these changes are reflected in the students' evaluations.

MEONF-II is a recently developed tool for screening of nutritional risk. It was developed to be used by nurses. Studies have shown promising sensitivity and accuracy compared to other screening instruments ${ }^{[3-5]}$, and its user-friendliness has been shown to be excellent among registered nurses ${ }^{[3,5]}$. However, it remains to be determined how it is experienced by undergraduate nursing students. It is also unknown how MEONF-II relates to other common clinical problems (e.g., insomnia, depressive mood and dependence in activities of daily living), and whether its user-friendliness differ depending on patients' degrees of dependency in activities of daily living (ADL).

The relationship between depression and undernutrition is well known ${ }^{[12,13]}$, and so is the relationship between undernutrition and ADL dependency ${ }^{[14,15]}$. However, less is known about the potential relationship between insomnia and undernutrition.

\section{Aim}

The aims of this study were to explore: 1) nursing students' perceptions of knowledge development after participating in an actual research project; 2) undernutrition and its relationship to other clinical factors; 3) the user-friendliness of the Minimal Eating Observation and Nutrition Form (MEONF-II) in relation to ADL dependency.

\section{Methods}

\subsection{Study design}

The study had a cross-sectional design.

\subsection{Context of nursing education}

In Sweden the nursing education is three years (six semesters), i.e. 180 ECTS (European Credit Transfer and Accumulation System). Successful completion of the programme leads to two degrees: registered nurse (RN) and bachelor of science in nursing (BSN). The nursing programme within which this study was conducted included $46 \%$ theoretical courses, $12 \%$ pre-clinical courses and $42 \%$ clinical courses. The programme includes continuous and progressing 
scientific training regarding evidence based practice, the research process, research methods, and (during the fifth semester) a 15 ECTS Bachelor's thesis.

\subsection{The study}

First ( $\mathrm{n}=64)$ and third year nursing students ( $\mathrm{n}=124)$ collected the data (three patients each), as an educational assignment, during one day of their clinical practice courses, in hospitals or nursing homes. The nursing students got written and oral information (one hour) about the study. The written information included study background, aim, instruments and procedures. They were also provided with an information letter to the managers as well as another one to the patients. Patients received written and oral information by the students ${ }^{[2]}$.

A pilot study (Study 1, S1) was conducted in October 2010, including 281 patients. After extending the research protocol a second data collection (Study 2, S2) was conducted in March 2011, including 236 patients. Thus, in total 517 patients were included in the study ( $\mathrm{n}=385$ patients in hospitals; $\mathrm{n}=132$ residents in special accommodations). In 2010 it was 104 nursing students involved in data collection ( $\mathrm{n}=31$ year one students and 73 year three students) and in 2011 it was 84 students ( $\mathrm{n}=33$ year one students and 51 year three students), in total 188 students.

\subsection{Instruments}

\subsubsection{Perceived knowledge development}

The students own perception of knowledge development was captured (in S1 and S2) by using two questions ${ }^{[11]}$, i.e. by participating in this study: 1) did your understanding of research improve; 2) did your knowledge about nutrition increase?

\subsubsection{Activities in daily living (ADL)}

ADL dependence was assessed (in S1 and S2) using a modified Katz Activities in Daily Living-index (Katz ADLindex ${ }^{[16]}$ which summarizes an individual's overall performance in six functions: hygiene; dressing and undressing; ability to go to the toilet; mobility; ability to control bowels and bladder; and food intake. In the original version the ability to perform each function is graded as independent, partly dependent or independent ${ }^{[16]}$. However, in this study the grading was only independent or dependent. Patients were then classified as almost totally dependent (needed help in 5 or 6 activities), partly dependent (needed help in 3 or 4 activities), or almost totally independent (needed help in 2 activities or less). The goal was that each student should assess one patient from each group of ADL dependency.

\subsubsection{Undernutrition risk}

Minimal Eating Observation and Nutrition Form - Version II (MEONF-II) was used to screen for undernutrition risk (in S1 and S2). MEONF-II includes an assessment of eating difficulties (according to the Minimal Eating Observation Form Version II (MEOF-II) ${ }^{[8]}$, unintentional weight loss, either low BMI $(<20$ for 69 years or younger, or $<22$ for 70 years or older) or calf circumference $<31$ centimetres, and an additional assessment of the presence or absence of clinical signs of undernutrition ${ }^{[3]}$. MEONF-II yields a total score ranging from 0-8. A score of $0-2$ is interpreted as low risk for undernutrition, a score of 3-4 is considered a moderate risk, and a score $\geq 5$ as high risk for undernutrition ${ }^{[4]}$. MEONF-II has shown a sensitivity of $0.61-0.73$, specificity $0.79-0.88$, and accuracy of $0.68-0.82$ when compared with the MNA ${ }^{[3,5]}$.

\subsubsection{I nsomnia}

The Minimal Insomnia Symptom Scale (MISS) was used to screen for insomnia (in S2) ${ }^{[17,18]}$. MISS is a scale focusing on three core aspects of insomnia, i.e. difficulties falling asleep, night awakenings, and not being rested by sleep. Each of the three questions are graded between 0 (none) and 4 (very severe). The sum varies between 0 and 12 points; six points or more is considered indicative of insomnia ${ }^{[17]}$. 


\subsubsection{Low-spiritedness}

A single-item was used to capture low-spiritedness as a crude indicator of depressed mood (in S2): "Today/during the last days I have felt gloomy and depressed" (graded as: not at all; yes, a little; yes, quite a lot; a lot) ${ }^{[19,20]}$.

\subsubsection{Subjective health}

A single-item was used as a crude indicator of subjective health (in S2): "In comparison with other people of the same age, how do you perceive your health status?" (graded as: not as good as others; as good as others; better than others) ${ }^{[21]}$.

\subsubsection{User-friendliness of MEONF-I I}

User-friendliness of the MEONF-II was evaluated (in S1 and S2) by inquiring the assessors of their perceived ease of understanding and following instructions, ease of understanding and completing items, and whether items were perceived as relevant. This was done following each patient assessment. These questions have previously been used to assess the user-friendliness of the MEONF-II ${ }^{[3-5]}$.

\subsection{Analysis}

For comparisons between independent groups Mann-Whitney U test, Chi-Square test and ANOVA were used ${ }^{[22]}$. Logistic regression analysis was used to test the association between undernutrition (dependent variable) and other clinical factors (independent variables). The decision about what independent variables to enter into the logistic regression analysis (enter method) was based on significances found in bivariate analysis. In addition, age and gender were also included in the model to control for these variables. Age was included as a continuous variable, gender was coded as $0=$ woman and $1=$ man, insomnia as $0=$ no insomnia and $1=$ insomnia (total MISS score $\geq 6$ ), ADL dependency in less than three ADLs was used as reference, and in low-spiritedness "no" was used as reference. Response categories "yes, a lot" and "yes, quite a lot" of the low-spiritedness item were merged for the logistic regression analyses due to a very low response frequency in the former category. Model fit was checked by the omnibus test (a $p$-value $<0.05$ indicates that the current model outperforms the null model) and the Hosmer and Lemeshow goodness-of-fit statistics (good model fit is indicated by a $p$-value $>0.05$, indicating no differences in actual and predicted dependent values) ${ }^{[23]}$. Analyses were conducted using PASW Statistics 18.0 .

\subsection{Ethical considerations}

All participants provided informed consent following written and oral study information. It was stressed that participation was on a voluntary basis, and that it would be possible to withdraw without any consequences for their care. No names and no personal identification numbers were collected. Formal approval by ethical committee was not required for this kind of study according to national and local directives ${ }^{[24]}$.

\section{Results}

Among the nursing students $67 \%$ (2nd semester, 67\%; 6th semester, 66\%, $p=0.905$ ) experienced that their understanding for research improved by participating and 52\% (2nd semester, 50\%; 6th semester, 54\%, $p=0.655$ ) that their knowledge about nutrition increased (see Table 1).

Table 1. Nursing students' perceptions of knowledge development after participating in an actual research project

\begin{tabular}{llll}
\hline & \multicolumn{2}{c}{ Nursing students (n=188) } \\
\cline { 2 - 4 } & $\mathbf{2}^{\text {nd }}$ semester $(\mathbf{n}=\mathbf{6 4})$ & $\mathbf{6}^{\text {th }}$ semester $(\mathbf{n = 1 2 4 )}$ & $\boldsymbol{p}^{\text {-value }}{ }^{{ }^{*}}$ \\
\hline Improved understanding for research, \% & 67 & 66 & 0.905 \\
Increased knowledge about nutrition, \% & 50 & 54 & 0.655 \\
\hline${ }^{*}$ Chi-square test & & &
\end{tabular}


Demographic patient data and descriptive data from patient assessments are reported in Table 2. The mean age of the participants was 78 years and most were female (57\%) hospitals inpatients (75\%). Most participants had circulatory (54\%) or pulmonary diseases $(27 \%), 50 \%$ were dependent in two or less activities of daily living and the other (50\%) were dependent in three activities or more. About a quarter (26\%) of the participants rated their health as being "not as good as others", $46 \%$ experienced some degree of low-spiritedness and 32\% had insomnia (see Table 2).

Table 2. Characteristics of respondents and their nutritional status.

\begin{tabular}{|c|c|}
\hline Item & $\mathbf{n}=\mathbf{5 1 7}$ \\
\hline Age, mean (SD) & $78.0(76.8-79.2)$ \\
\hline Gender, men/women, \% & $43 / 57$ \\
\hline \multicolumn{2}{|l|}{ Setting, $\%$} \\
\hline Hospital & 75 \\
\hline Special accommodations & 25 \\
\hline \multicolumn{2}{|c|}{ The five most common diagnose categories, $\%$} \\
\hline Circulation & 54 \\
\hline Pulmonary & 27 \\
\hline Orthopaedic & 19 \\
\hline Gastroenterology & 15 \\
\hline Endocrinology & 15 \\
\hline \multicolumn{2}{|l|}{ Activities of daily living, $\%$} \\
\hline Dependent in two activities or less & 50 \\
\hline Dependent in three or four activities & 27 \\
\hline Dependent in five or six activities & 23 \\
\hline \multirow[t]{2}{*}{ Moderate/high undernutrition risk ${ }^{*}, \%$} & 48 \\
\hline & $\mathrm{n}=256^{\#}$ \\
\hline \multicolumn{2}{|c|}{ Subjective health, comparison to others in about same age, \% } \\
\hline Not as good as others & 26 \\
\hline As good as others & 51 \\
\hline Better than others & 23 \\
\hline \multicolumn{2}{|l|}{ Low-spiritedness, \% } \\
\hline Not at all & 54 \\
\hline Yes, a little & 26 \\
\hline Yes, quite a lot & 14 \\
\hline Yes, a lot & 6 \\
\hline Insomnia ^ , \% & 32 \\
\hline
\end{tabular}

Among patients at moderate/high undernutrition (UN) risk it was significantly more common with ADL dependency, with insomnia, and with low-spiritedness (see Table 3). There was no association between undernutrition and perceived health (see Table 3).

Results from the logistic regression analysis are presented in Table 4. ADL dependency and insomnia showed independent significant associations with UN risk, exhibiting about a 2-2.5 fold increase in odds. Compared to dependency in 0-2 ADLs, dependency in 5-6 ADLs (OR 2.439) and dependency in 3-4 ADLs (OR 2.057) were the strongest of the significant predictors for undernutrition risk, followed by insomnia (OR 2.124). There was no significant association between low-spiritedness and UN risk (see Table 4). 
Table 3. Comparisons between persons with no/low risk for undernutrition (UN) and those with moderate/high risk $(\mathrm{n}=256)$.

\begin{tabular}{|c|c|c|c|}
\hline \multirow{2}{*}{ Item } & \multicolumn{2}{|c|}{ UN-risk * } & \multirow[b]{2}{*}{$P$-value ${ }^{\#}$} \\
\hline & No/low & Moderate/high & \\
\hline Activities of daily living (\%) & & & $<0.001$ \\
\hline Dependent in two activities or less & 62 & 37 & \\
\hline Dependent three or four activities & 23 & 31 & \\
\hline Dependent in five or six activities & 15 & 32 & \\
\hline Subjective health, comparison to others in about same age (\%) & & & 0.170 \\
\hline Not as good as others & 23 & 30 & \\
\hline As good as others & 51 & 51 & \\
\hline Better than others & 26 & 19 & \\
\hline Insomnia (\%) & 24 & 48 & $<0.001$ \\
\hline Low-spiritedness (\%) & & & 0.002 \\
\hline Not at all & 59 & 45 & \\
\hline Yes, a little & 27 & 25 & \\
\hline Yes, quite a lot & 12 & 19 & \\
\hline Yes, a lot & 2 & 11 & \\
\hline
\end{tabular}

* According to the Minimal Eating Observation and Nutrition Form-Version II (MEONF-II). \# Mann Whitney U-test. † According to the Minimal Insomnia Symptom Scale (MISS)

Table 4. Logistic regression analysis with undernutrition risk as dependent variable $(0=$ no/low risk, $1=$ moderate $/$ high risk according to MEONF-II) $(\mathrm{n}=256)^{*}$

\begin{tabular}{lllll}
\hline & Odds Ratio & \multicolumn{2}{c}{ 95\% CI } & P-value \\
\hline Age & 0.994 & 0.974 & 1.015 & 0.588 \\
Gender (male=1) & 0.741 & 0.405 & 1.356 & 0.331 \\
Insomniab) $^{\text {Activities of daily living (ADL) }}{ }^{\dagger}$ & 2.124 & 1.107 & 4.074 & 0.023 \\
$\quad$ Dependent in 3-4 ADLs & & & 0.032 \\
$\quad$ Dependent in 5-6 ADLs & 2.057 & 1.020 & 4.145 & 0.044 \\
Low-spiritedness & 2.439 & 1.130 & 5.266 & 0.023 \\
$\quad$ Yes, a little & & & & 0.225 \\
$\quad$ Yes, quite a lot/a lot & 0.920 & 0.446 & 1.896 & 0.821 \\
\hline
\end{tabular}

* Omnibus test of goodness-of-fit, $P=0.001$; Hosmer \& Lemeshow test of goodness-of-fit, $P=0.781$; Nagelkerke R square, 0.139 . \# According to the Minimal Insomnia Symptom Scale (MISS).

$\dagger$ Reference category (coded 0$)=$ dependence in 0-2 ADLs. CI, Confidence Interval

Table 5. Nursing students' $(\mathrm{n}=188$ ) perception of the MEONF-II user-friendliness in relation to patients' ADL (Activities in Daily Living).

\begin{tabular}{|c|c|c|c|c|c|}
\hline & $\begin{array}{l}\text { Dependent in } \\
\leq 2 \text { activities } \\
(n=254)\end{array}$ & $\begin{array}{l}3-4 \text { activities } \\
(n=137)\end{array}$ & $\begin{array}{l}\text { 5-6 activities } \\
(n=118)\end{array}$ & $P$-value & Total $(n=509)^{\dagger}$ \\
\hline Time (minutes) to complete, mean (SD) & $11.1(8.7)$ & $10.8(6.1)$ & $12.8(9.1)$ & $0.143^{*}$ & $11.3(8.1)$ \\
\hline $\begin{array}{l}\text { The MEONF-II manual is easy to } \\
\text { understand, } \%\end{array}$ & 93 & 95 & 90 & $0.386^{\#}$ & 93 \\
\hline $\begin{array}{l}\text { The MEONF-II questions are easy to } \\
\text { answer, } \%\end{array}$ & 95 & 92 & 93 & $0.602^{\#}$ & 94 \\
\hline The MEONF-II questions are relevant, $\%$ & 93 & 94 & 95 & $0.792^{\#}$ & 94 \\
\hline $\begin{array}{l}\text { Relevant suggestions for measures to take } \\
\text { in case of risk, } \%\end{array}$ & 95 & 95 & 95 & $0.999^{\#}$ & 95 \\
\hline
\end{tabular}

* ANOVA. \# Chi-square test. $\uparrow$ Missing ratings of user-friendliness in eight cases (original sample $\mathrm{n}=517$ ). Minimal Eating Observation and Nutrition Form-Version II (MEONF-II) 
It took a mean of 11 minutes to perform the screening with MEONF-II; which did not differ according to patients' levels of ADL dependency (see Table 5). The nursing students ( $\mathrm{n}=188)$ experienced the MEONF-II manual as easy to understand $(93 \%)$, questions as easy to answer (94\%), the questions as relevant (94\%) and the suggestions for measures to take in case of risk as relevant (95\%). User-friendliness was independent of the patients' level of dependency in ADL (see Table 5).

\section{Discussion}

This study supports that participating in an actual research project improves nursing students understanding for research as well as for the area under study. As suggested in a previous study ${ }^{[2]}$, this should facilitate students' ability to work with quality improvements in their future role as professional nurses. We also obtained evidence that undernutrition is associated with ADL dependency and with insomnia, and that the MEONF-II is perceived as user-friendly regardless of patients' levels of ADL dependency.

Involving a relatively large number of nursing students in data collection may be seen as a weakness challenging data quality. However, involving many different assessors also reflects clinical practice, i.e. the study can be viewed as a naturalistic study. Furthermore, the rates of moderate/high risk of undernutrition in this study is very similar to that reported in other studies using a restricted number of registered nurses for data collection ${ }^{[3,4]}$ with good inter-rater reliability (kappa, 0.81$)^{[25]}$ in this type of patient populations. Also other aspects of our observations support accuracy of data as they replicate previous findings (see below). Students were asked to assess three patients with different levels of dependency. As can be seen in the results, $50 \%$ of patients were dependent to a limited extent (in two or less activities). This might reflect that it was difficult to get informed consent from patients with more dependency, or that there were actually more patients with low level of dependency in the specific settings.

Involvement of nursing students in actual research projects as an educational assignment enhances their understanding for research, and increase their knowledge within the area of the study. About two thirds of the students experienced that their understanding for research improved, and about half that their knowledge about nutrition increased. A similar pattern was seen in an earlier study, reporting that $38 \%$ experienced increased knowledge about nutrition and $86 \%$ stated an improved understanding of research ${ }^{[1]}$. The differences in figures are likely due to several reasons. For example, there are uncertainties associated with the figures from the earlier study due to its limited sample size $(n=42)$. Furthermore, since then there have been changes in the nursing education, with an increased emphasis on research related areas and less nutrition specific education. However, the important finding is that learning is enhanced by participating in an actual research project, as also shown in a recent qualitative study ${ }^{[2]}$. Adding to this, others have found that participating in research leads to more positive attitudes towards research ${ }^{[6]}$ and improved research skills ${ }^{[6,7]}$.

Previous studies are pointing towards an association between undernutrition and depressed mood ${ }^{[12,13,26,27]}$, something that was not confirmed in this study, when taking ADL and insomnia into account. However, in this as well as in other studies ${ }^{[14,15]}$ an association between undernutrition and ADL dependency was shown. A finding that might be seen as somewhat unexpected was the relationship between impaired nutritional status and insomnia. As far as we know, this has not been shown before. However, an association between insomnia and low consumption of specific nutrients was recently shown in a study from India among 87 adults (age 21-45 years) ${ }^{[28]}$. In addition, in a recent study from Malaysia, an association has been shown between insomnia and high wastage of vegetables, among 71 elderly (mean 69.5 years) people in a government-funded institution ${ }^{[29]}$. Although these two studies ${ }^{[28,29]}$ did not focus on the relationship between insomnia and undernutrition per see, the findings are suggestive of such a relationship. Thus, sleep status and nutritional status seems to be interdependent. However, it remains to be determined whether poor sleep may cause undernutrition, or whether undernutrition contributes to deteriorated sleep. In addition, it is known since long that insomnia is associated with a high rate of co-morbidity ${ }^{[30]}$, which might increase the risk for compromised nutritional status. It is therefore possible that factors not considered in the current study may underpin the observed associations. Taken together, our observations could be viewed as suggestive of a complex triad of coexisting problems, i.e. between undernutrition - 
mental - and physical factors. However, it remains unclear what constitutes the causes and consequences and the current cross-sectional study design does not allow any firm conclusions in this regard. These associations are clearly an area in need of further studies.

The user-friendliness of the MEONF-II was excellent, regardless of patients' levels of ADL dependence. This is in accordance with previous observations among registered nurses ${ }^{[3,5]}$. However, this is the first evidence that this is the case regardless of patients' levels of ADL dependency. This is important since problems in using a screening tool among subsets of people (eg, those with high levels of ADL dependence) severely limit its usefulness in clinical practice. To the best of our knowledge, this is the first study to document this critical aspect of a nutrition screening tool.

\section{Conclusions}

Participating in actual research projects enhance students learning about research as well as within the area of the study. Undernutrition, physical (ADL dependency) and mental problems (insomnia) constitute coexisting problems in need for further investigation. The MEONF-II is perceived as a user-friendly and relevant nutritional screening tool.

\section{Acknowledgement and funding}

The authors wish to thank all participating patients, students and nurses for their cooperation. Especially thanks to Emma Lindgren for her valuable help with data input, and to the Swedish House in Kavalla, Greece. The study was supported by the Swedish Research Council.

\section{References}

[1] SFS: The Swedish Higher Education Act (SFS 1992:1434). In. Sweden: Ministry of Education and Research; 1992.

[2] Westergren A, Edfors E. Nursing students gain tools for knowledge utilisation through a work and research integrated learning assignment - a qualitative study. Journal of Nursing Education and Practice. 2013; 3(1). http://dx.doi.org/10.5430/jnep.v3n1p60

[3] Westergren A, Norberg E, Hagell P: Diagnostic performance of the Minimal Eating Observation and Nutrition Form - Version II (MEONF-II) and Nutritional Risk Screening 2002 (NRS 2002) among hospital inpatients - a cross-sectional study. BMC nursing. 2011; 10: 24. PMid:22185436 http://dx.doi.org/10.1186/1472-6955-10-24

[4] Westergren A, Norberg E, Vallen C, Hagell P. Cut-off scores for the Minimal Eating Observation and Nutrition Form - Version II (MEONF-II) among hospital inpatients. Food \& nutrition research. 2011: 55.

[5] Vallen C, Hagell P, Westergren A: Validity and user-friendliness of the minimal eating observation and nutrition form - version II (MEONF - II) for undernutrition risk screening. Food \& nutrition research. 2011; 55.

[6] Duggleby W: Improving undergraduate nursing research education: the effectiveness of collecting and analyzing oral histories. The Journal of nursing education. 1998; 37(6): 247-252. PMid:9749810

[7] Gaskamp CD: Teaching research utilization in a baccalaureate nursing program. Nurse educator. 1997; 22(3): $39,44$.

[8] Westergren A, Lindholm C, Mattsson A, Ulander K: Minimal eating observation form: reliability and validity. The journal of nutrition, health \& aging. 2009; 13(1): 6-12. PMid:19151901 http://dx.doi.org/10.1007/s12603-009-0002-4

[9] Westergren A, Lindholm C, Axelsson C, Ulander K: Prevalence of eating difficulties and malnutrition among persons within hospital care and special accommodations. The journal of nutrition, health \& aging. 2008; 12(1): 39-43. PMid:18165843 http://dx.doi.org/10.1007/BF02982162

[10] Westergren A, Wann-Hansson C, Borgdal EB, Sjolander J, Stromblad R, Klevsgard R, Axelsson C, Lindholm C, Ulander K: Malnutrition prevalence and precision in nutritional care differed in relation to hospital volume - a cross-sectional survey. Nutrition journal. 2009; 8: 20. PMid:19422727 http://dx.doi.org/10.1186/1475-2891-8-20

[11] Ulander K, Westergren A, Axelsson L, Lindholm C: Building practice knowledge by assessing eating and malnutrition in a point prevalence study. In: ESPEN Istanbul. 2006.

[12] Saka B, Kaya O, Ozturk GB, Erten N, Karan MA: Malnutrition in the elderly and its relationship with other geriatric syndromes. Clin Nutr. 2010; 29(6): 745-748. PMid:20627486 http://dx.doi.org/10.1016/j.clnu.2010.04.006 
[13] Vanderwee K, Clays E, Bocquaert I, Gobert M, Folens B, Defloor T: Malnutrition and associated factors in elderly hospital patients: a Belgian cross-sectional, multi-centre study. Clin Nutr. 2010; 29(4): 469-476. PMid:20097458 http://dx.doi.org/10.1016/j.clnu.2009.12.013

[14] Westergren A, Unosson M, Ohlsson O, Lorefalt B, Hallberg IR: Eating difficulties, assisted eating and nutritional status in elderly ( $>$ or $=65$ years) patients in hospital rehabilitation. International journal of nursing studies. 2002; 39(3): 341-351. http://dx.doi.org/10.1016/S0020-7489(01)00025-6

[15] Amaral TF, Matos LC, Teixeira MA, Tavares MM, Alvares L, Antunes A: Undernutrition and associated factors among hospitalized patients. Clin Nutr. 2010; 29(5): 580-585. PMid:20207055 http://dx.doi.org/10.1016/j.clnu.2010.02.004

[16] Katz S, Akpom CA: 12. Index of ADL. Med Care. 1976; 14(5 Suppl): 116-118. PMid:132585 http://dx.doi.org/10.1097/00005650-197605001-00018

[17] Broman JE, Smedje H, Mallon L, Hetta J. The Minimal Insomnia Symptom Scale (MISS): a brief measure of sleeping difficulties. Uppsala journal of medical sciences. 2008; 113(2): 131-142.

[18] Hellstrom A, Hagell P, Fagerstrom C, Willman A: Measurement properties of the Minimal Insomnia Symptom Scale (MISS) in an elderly population in Sweden. BMC geriatrics. 2010; 10: 84. PMid:21054878 http://dx.doi.org/10.1186/1471-2318-10-84

[19] Tibblin G, Bengtsson C, Furunes B, Lapidus L: Symptoms by age and sex. The population studies of men and women in Gothenburg, Sweden. Scandinavian journal of primary health care. 1990; 8(1): 9-17. PMid:2356375 http://dx.doi.org/10.3109/02813439008994923

[20] Stenzelius K, Westergren A, Thorneman G, Hallberg IR: Patterns of health complaints among people 75+ in relation to quality of life and need of help. Archives of gerontology and geriatrics. 2005; 40(1): 85-102. PMid:15531026 http://dx.doi.org/10.1016/j.archger.2004.06.001

[21] Guigoz Y, Vellas B: The Mini Nutritional Assessment (MNA) for grading the nutritional state of elderly patients: presentation of the MNA, history and validation. Nestle Nutrition workshop series Clinical \& performance programme. 1999; 1: 3-11; discussion 11-12. PMid:11490593 http://dx.doi.org/10.1159/000062967

[22] Altman DG: Practical statistics for medical research, 2 edn: Taylor \& Francis; 1991.

[23] Hair J, Anderson R, Tatham R, Black W: Multivariate Data Analysis. London: Prentice-Hall International; 1998.

[24] SFS: Lag om etikprövning av forskning som avser människor [The Act concerning the Ethical Review of Research Involving Humans on the website of the Central Ethical Review Boards]. 2003.

[25] Westergren A, Vallén C: Validity and reliability of Minimal Eating Observation and Nutrition Form (MEONF). Clinical Nutrition Supplements. 2010; 5(2): 61. http://dx.doi.org/10.1016/S1744-1161(10)70174-5

[26] Smoliner C, Norman K, Wagner KH, Hartig W, Lochs H, Pirlich M: Malnutrition and depression in the institutionalised elderly. The British journal of nutrition. 2009; 102(11): 1663-1667. PMid:19622192 http://dx.doi.org/10.1017/S0007114509990900

[27] Westergren A: Nutrition and its relation to mealtime preparation, eating, fatigue and mood among stroke survivors after discharge from hospital - a pilot study. The open nursing journal. 2008; 2: 15-20.

[28] Zadeh SS, Begum K: Comparison of nutrient intake by sleep status in selected adults in Mysore, India. Nutrition research and practice. 2011; 5(3): 230-235. PMid:21779527 http://dx.doi.org/10.4162/nrp.2011.5.3.230

[29] Shahar S, Hassan J, Sundar VV, Kong AY, Ping Chin S, Ahmad SA, Kuan Lee L: Determinants of depression and insomnia among institutionalized elderly people in Malaysia. Asian journal of psychiatry. 2011; 4(3): 188-195. PMid:23051116 http://dx.doi.org/10.1016/j.ajp.2011.06.001

[30] Gislason T, Almqvist M: Somatic diseases and sleep complaints. An epidemiological study of 3,201 Swedish men. Acta medica Scandinavica. 1987; 221(5): 475-481. PMid:3496735 http://dx.doi.org/10.1111/j.0954-6820.1987.tb01283.x 